Reviews

is their ability to establish a certain degree, however precarious, of economic independence, to be able to function outside the political economy that is firmly in the hands of the power elite.

Finally, Duncan turns to rural New England, only to find a place where poverty is less severe, the exploitive class system of patron-client relationships is missing, and the prospect for getting out of poverty for individuals is real. (This is the part of the book that is going to have diehard Southerners grinding their teeth.) The families that started the paper mills that served as the foundation of the economy in this area were interested in having a welleducated and well-paid workforce, so they supported the establishment of good schools and unions early on. The social differentiation that occurred never solidified into the two-class system of the other areas. ãEverybodyä went to the same school and participated in the same social system. No one was made to feel inferior because, perhaps, their clothes were not quite as nice or their car was not of the era.

Furthermore, and because of the greater equality, there developed within the town the kind of positive social sentiments and interlocking social networks that Robert Putnam calls ãsocial capital.ä Upkeep and improvement of the school, the development of programs for young people, and a grass-roots anti-poverty initiative all emerged within the civic society that Putnam argues is a function of high levels of social capital.

In the final section, Duncan makes her theoretical orientation explicit, placing herself in a theoretical space defined by the intersection of a classic British view of social class, melded with the cultural sociology of Ann Swidler. And she goes on to suggest policy initiatives to deal with persistent rural poverty. She has two major recommendations. First, she is positively disposed toward those policy analysts who call for new public works projects to provide employment where the private sector will not, along with a fortified income safety net for families. She is also appropriately skeptical about such a thing occurring. Second, she favors a strong federal role in schools, one that will enforce standards and turn schools from human warehouses to true socialization agents and providers of opportunity.

I will leave the readers of her work to decide on the appropriateness of her policy recommendations. As a way of concluding, I want to emphasize the subtlety and insight of her analyses. In contemporary debates about structure and agency, in many respects attributing a thoroughgoing agency is in vogue. To some readers, then, her desire to bring broad social norms regarding middle class life in America into the explanation will be too oldfashioned, too ãmodernist.ä But the ability, or lack thereof, to approximate these expectations of a ãdecentä (in Veblenâs sense of the term) life the lived experience of poverty for people. Their lives are a combination of exploited dependency and the impossibility of being just ãordinary.ä Examining how this works in the broad context of economic history and social class processes in rural areas is a singular accomplishment of Duncanâs work. I highly recommend the book.

\title{
At the Interface: The Household and Beyond. Monographs in Economic Anthropology Series, No. 15. Edited by David B Small and Nicola Tannenbaum. Lanham, NY: University Press of America (1999), 240 pp.
}

\section{Reviewed by Michael P. Freedman, Department of Anthropology, The Maxwell School of Syracuse University.}

The "interface," used variably and understood intuitively in this volume, is the connection between units of sociological interest, such as households and sodalities, the village and the state, individuals and the market. Originally prepared for the 1996 meeting of the Society of Economic Anthropology and for a session of the AAA annual conference, most of the dozen papers comprising this volume share a focus on the household, emphasizing one or another of its connections within the community and beyond.

Four papers treating intracommunity interfaces examine producer cooperatives in Sri Lanka and Mexico, age sets among the Samburu, and the culture of labor exchange among Andean peasants. 
Reviews

A second unit, on single communities and their connections with state government and the market, includes a study of a Shan village in Thailand that has become increasingly market oriented, cash dependent, and Thaiintegrated; a paper that traces the shift from self-sufficient, albeit market-oriented seal hunting in an East Greenlandic village to a reliance on state subsidies following the European Union's ban on seal skins; and an article that considers how inter-household sharing among the Kalahari Basarwa, rather than territory or formal kinship, defines for them the community.

Two papers on household-based businesses in northern Ghana and Java explore what the editors style "Extracommunity Interfaces." In the case of Ghana, the commercial production of shea butter (from oil seed) follows a familiar trajectory - one in which small operators are marginalized and ultimately squeezed out of the market. Furniture production in Java, on the other hand, offers an interesting example of specialized niche survival and indeed success that entails the contractual coupling of disparate specialists in the making of a final product that is bought up by international furniture dealers.

Perhaps the most theoretically explicit papers are the two that apply the interface concept to archaeological site data. One examines the effects of population growth, land-disenfranchisement, and access to credit upon levels of household productivity in a Yucatecan hacienda, rancho, and pueblo between 1750 and 1847. Production intensified on the first two, but the pueblo successfully limited population size and retained ample household land so that it was unnecessary to raise productivity per acre (and presumably the intensity of the labor effort). The second article considers the effects of human population growth and livestock growth on Navajo multi-household settlement. Population growth encouraged dispersed settlements, while growth in herd size promoted settlements that were more clustered but smaller.

In the closing essay, the editors offer "some conclusions." The interface concept, they write, obliges us "to re-think our standard analytic units." "The cases presented a wide range of household and community structures, and it is clear there is no single definition that can encompass all the examples." While households are often nuclear family units of production, consumption, and sharing, among the Basarwa "sharing networks and the production and consumption that they assume are so broad as to encompass whole camps, which expands 'household' to contain the whole community." (But of course, the Basarwa and we are clear that the household or hearth group is conceptually distinct from the sharing network, however much the latter is implicated in the distribution of goods.) By contrast, the sharing motif is muted if not missing from the Javanese furniture makers and the Ghanaian shea producers, where separate budgets for husband and wife are common, and little pooling of resources is evident.

The editors urge that household and community should be seen, not as organizational forms, but as "clusters of interactions." Said interactions are ways of behaving that are "defined by local context" and "history." Indeed, the interactions in question are "structured" by household and community interfaces, yielding different orientations to production -- the "peasant" type, "production for international markets," and "responses to international markets."

It will be apparent to the reader that these are, of course, not conclusions of real substance. Nor are these observations about household variability news to students of Anthropology 101. To this reader, they are lifelessly abstract and rhetorically platitudinous. I think this unfortunate result obtains in large measure because the concept "interface" is ill defined, weakly conceived, and under-theorized. Granted, there is much that is useful in looking at relations, linkages, connections between identifiable entities, and in viewing them within the context of access to resources. But notwithstanding the novel nomenclature, there is nothing present, theoretically or methodologically, in "interfaces" that has not been intrinsic to established social science inquiry for years.

The editors write, "Our theoretical perspective in looking at the interface is one that images clusters of people [households] and clusters of clusters of people [communities] in the context of larger political and economic structures which impinge on, structure and limit people's ability to act and interact." Conceivably, the clustering concept could be applied ad infinitum. But on balance, what would we gain in conceiving of an abstract third-order cluster rather than in conceptualizing, say, a nation-state, a trans-national corporation, an organized church, or an international revolutionary movement?

This abstract nomenclature is not a necessary entailment of a formal theory. Employing abstract terminology so pervasively impedes grasping in a vivid, "filmable" way what in fact is going on. Is the "interface" a place -where the rubber hits the road, a coupling structure, a process?

Ordinarily, we might speak of an "interface" to denote a shared surface or boundary between two bodies, as the wall between adjoining rooms, or the subset of knowledge and intellectual pursuits common to physics and chemistry. In the present volume, however, "interface" often is unbounded on one side (interfaces beyond the local level). Or, if bounded on both sides (the interface between the household and the market), the interface is less something shared by both sides than an imbalanced force field.

The culture and sociology of academia appears to influence scholars to develop a jargon whether or not it is needed to enable technical communication. These papers could just as well have appeared in a volume entitled 
Reviews

"Social Influences upon the Household" or "Households and the Political Economy." The metaphor of "frontier" or "bonding" or "co-participation" could as well have served as "interface."

The ethnographic and archaeological papers in At the Interface are sturdy, mostly descriptive reports that can be read and utilized apart from the theoretical "spin." Regrettably, the volume lacks an index. To a considerable extent, the cases document the globalizing spread of world trade into exotic, backwater localities, and with it, the growth or accentuation of class differences, a raised standard of living, consumerism, and tendencies toward individualism. But the accounts also detail some of the limitless ways in which people adapt and accommodate; negotiate the obstacles and opportunities presented by the market and the state; and preserve or reconfigure their communities and their identities.

\section{Spirit Wars: Native North American Religions in the Age of Nation Building, by Ronald Niezen, London and Los Angeles: University of California Press (2000), 256 pp.}

\section{Reviewed by Stephen Greymorning, Departments of Anthropology and Native American Studies, University of Montana.}

In Spirit Wars, Ronald Niezen has masterfully researched the impact colonization has had on the religious practices of Indigenous North Americans. If influenced by initial appearances the book would appear overly ambitious, by its effort to address a multitude of events from a variety of geographic regions and time periods through subjects ranging from missionary and government intrusions to that of New Age mentalities. Solid research and scholarship, however, ground the book and give readers insight into a world of cultural domination and religious suppression rarely seen and most often misunderstood. Readers further benefit from several essays by Native contributors writing on how individual Native people and communities have been affected both historically and contemporarily by activities aimed at alienating Indigenous North Americans from their cultural ways of being.

Following his introductory chapter, Niezen sets about introducing readers to the rationale underlying early Spanish assaults on Native rituals and ceremonies; part of which included "making them amenable to White economic exploitation" (p. 39). Whether at the hands of missionaries or politicians, educating the "Indian" was a constant theme.

By the later part of the 1800s the marriage of evangelism and education became the modus operandi of the new Indian solution. In Chapter Three, Niezen exposes how the works of some of Europe's and America's greatest thinkers helped shape the world view of Anglo-Americans, which in turn yielded cultural forces that led a nation to believe it held a God-given right to shape a people in its own image. In one discussion Niezen holds the writings of Lewis Henry Morgan up as a mirror, reflecting the beliefs of a nation that perceived the best strategy for transforming Indian people's lives was through education and Christianity. The medium for this social experiment became the Indian residential schools, and the individual credited with bringing the needed structure to those schools was Lieutenant Richard Pratt.

From the onset the objective of the residential school was to convert Indians to White values. Niezen informs readers that Pratt believed the first step in this transformation was to physically change their appearance. While this had a devastating impact on many Indians, some also saw it as ludicrous.

When it was announced though [sic] an interpreter that their braids were to be shorn... Robert American Horse, made a speech... in which he concluded, "If I am to learn the ways of the White people, I can do it just as well with my hair on" (p. 62).

Most others, like Luther Standing Bear, were left feeling distraught. "After having my hair cut a new thought came into my head. I felt that I was no more Indian, but would be an imitation of a whiteman" (p. 63).

Thus after 200 years of failed missionary efforts to educate and assimilate Indians, Pratt's Indian residential school set the new standard. Niezen relates, however, that those standards brought with them the implementation of a level of punishment and control that became sadistic and often crossed over into the pathological. While it is common knowledge that Indians were punished for speaking their Native language, at the Alberni Indian residential school in Canada one individual revealed he was "punished for speaking Tseshalt by having sewing needles pushed 